\title{
Disruptive Innovation:
}

\section{A Case of Full Mold Casting}

\author{
Tomofumi TAKAMATSU ${ }^{\mathrm{a})}$ and Junichi TOMITA ${ }^{\mathrm{b})}$
}

\begin{abstract}
Regarding disruptive innovation, Christensen and Raynor (2003) assume that there are two types of customers: overshot customers in existing markets and entirely new nonconsumers in other markets. In the case of large-scale casting market within the casting industry, customers demand high quality casting surfaces. The new method of casting termed full mold casting (FMC) could only achieve low quality results compared with existing wood pattern-based sand mold casting, which had sufficiently high quality in its casting surfaces. Even in that market, however, the casting of metallic molds for automobiles had particular requirements because casting surfaces were later dealt by mold companies. Thus, customers welcomed shorter delivery times even with lower quality casting surfaces. Kimura Chuzosho Co., Ltd. first acquired certain customers who desired shorter delivery times, and then improved casting surface quality and productivity over the course of doing business with them. Eventually, they became successful in capturing more than half the market for automobile metallic mold castings. Improving
\end{abstract}

a) School of Business, Aoyama Gakuin University, 4-4-25 Shibuya, Shibuya-ku, Tokyo, Japan, takamatsu@busi.aoyama.ac.jp

b) Faculty of Business Administration, Toyo University, 5-28-20 Hakusan, Bunkyo-ku, Tokyo, Japan, tomita@toyo.jp

A part of this paper was originally published as Tomita and Takamatsu (2013) in Japanese and an earlier version of this paper was presented at the ABAS Conference 2014 Summer (Takamatsu \& Tomita, 2014). 
the quality of casting surfaces led to market share gains for single castings used in machine tools, which demanded higher mid-range casting surface quality. Moreover, by fully mechanizing numerical control (NC) processing, the company was able to acquire market share in castings for high-end mass-produced machine tools, which demanded high-end casting surface quality and was an area that was considered difficult for FMC. In this manner, by keenly focusing on the specific requirements of their customers, Kimura had secured orders from customers who were neither nonconsumers nor overshot customers. As business continued, the company became successful in steadily improving overall quality, cost, delivery (QCD), and FMC became an example of disruptive innovation vis-à-vis existing wood pattern-based sand mold casting. The logic behind occurrences of disruptive innovation is simpler than the analysis of Christensen, Anthony, and Roth (2004): Even if a company can acquire only a small portion of customers with particular, specific requirements using QCD-related technologies, which are perhaps even toy-like in comparison with existing technologies, such company will have opportunities to improve the overall QCD as its business continues.

Keywords: disruptive innovation, process innovation, metal casting industry, Kimura Chuzosho

\section{Introduction}

There exist sustaining innovations that improve product performance according to existing criteria. In addition, there exist disruptive innovations that can replace existing products, first improving product performance in a different set of criteria despite lower performance in the original criteria, and subsequently causing improvements according to existing product performance criteria (Christensen, 1997).

Christensen and Raynor (2003) assumed two types of customers with regard to disruptive innovation: entirely new nonconsumers in 
markets outside of existing markets, and overshot customers in existing markets. ${ }^{1}$ New-market disruptive innovations provide new value to nonconsumers through innovations for new markets that subsequently cause disruptive innovations in existing markets. Low-end disruptive innovations provide products and services that grant value in line with low-end overshot customers, but subsequently target customers from the high end (Christensen \& Raynor, 2003). Keywords for disruptive innovation are cost, traditional performance, and ancillary performance change (Utterback \& Acee, 2005). ${ }^{2}$ While new-market disruptive innovations may lag in traditional performance, they acquire new markets with innovations in superior ancillary performance and permeate from new markets to existing markets. On the other hand, low-end disruptive innovations exhibit poor traditional performance; nevertheless, innovations with lower costs enable them to withdraw customers from existing markets. 3 New-market disruptive innovations can also be used to replace products on the low end of existing markets; thus, conceptually, there is continuity between new-market and low-end disruptive innovations (Christensen \& Raynor, 2003).

Existing companies can respond to a sustaining innovation even when the innovation is radical; however, with disruptive innovation, existing companies often fail to form a response. This is because existing companies are bound by their existing value network in which they have developed a customer base and business

1 In addition to nonconsumers and overshot customers, Christensen, Anthony, and Roth (2004) also assume the existence of undershot customers. These are customers among an existing customer base that are unsatisfied by current products. They make it easier to generate sustaining innovations.

2 Utterback and Acee (2005) noted the necessity of seeing eight patterns of change by various combinations of increases or decreases in cost, traditional performance, and ancillary performance.

3 Customers value them as having not only lower cost but also being simpler. 
relationships (Christensen \& Rosenbloom, 1995). As understood through the value network, when a value network cannot respond to nonconsumers that demand new value, new-market disruptive innovations occur; when low-end customers are taken from a primary value network with existing products and services, the result is low-end disruptive innovation (Christensen \& Raynor, 2003).

Can we then assume that there are only two customer types, nonconsumers and overshot customers, with regard to customers who influence the value of a disruptive innovation? ${ }^{4}$ In Japan's large-scale casting industry, the full mold casting (FMC) method used by Kimura Chuzosho Co., Ltd. became a disruptive innovation that acquired customers with specific requirements unmet by existing wood pattern-based sand mold casting. These customers were neither nonconsumers nor overshot customers.

\section{Process Innovation of FMC}

As the name implies, a wood pattern is a pattern made from wood. Sand mold casting in the casting industry has extensively used these wood patterns. The wood patterns are filled with molding sand, and a mold is formed by solidifying the molding sand. The space created by the removal of the wood pattern is filled with melted metal, and a casting is formed. At present, medium- and small-scale castings are often made by using patterns of metal or plastic, while molds are

4 Some critics state that, from a technology perspective, it is unclear what is disruptive innovation and at the point at which an innovation becomes disruptive, making it possible to declare something disruptive after the fact (Danneels, 2004). The S-shaped technology curve has strong randomness, and existing technology cannot simply be substituted for disruptive technology. Thus, the view of existing vs. disruptive technologies is an oversimplification (Sood \& Tellis, 2005; Tellis, 2006). When we swap one metric for another, in some cases we can see that there are no differences between existing and disruptive technologies (Takahashi, Shintaku, \& Ohkawa, 2013). 
often formed with metal. However, even today, large-scale castings are made by using sand mold casting with wood patterns.

In contrast, FMC also uses molding sand, though it uses patterns made from foam polystyrene instead of wood patterns. In FMC, the pattern fills the interior of the mold, and subsequently melted metal replaces the pattern inside the mold, thereby forming a casting.

The process of wood pattern-based sand mold casting is as follows. 1) A wood pattern is formed (this pattern is a model of the finished product). 2) The top and bottom of a mold are prepared. 3) The wood pattern is placed in the mold and filled with sand. 4) As the sand solidifies, the wood pattern is removed. 5) The surface of the mold is coated with a slury of carbon, allowed to dry, and thereafter top and bottom portions are prepared. 6) The core of the mold, equivalent to the hollow portion of the casting, is then prepared. 7) The core is placed into the bottom part, and the top part is then combined. 8) The completed mold is filled with melted metal. 9) The casting is allowed to cool and solidify. 10) The casting is removed, processed, and polished.

In contrast, the process flow used by FMC is as follows: 1) A pattern is made from foam polystyrene. 2) The surface of the pattern is coated with a slury of carbon and allowed to dry. 3) The pattern is placed inside the mold and filled with sand. 4) When the sand solidifies, the mold is filled with melted metal. 5) The casting is allowed to cool and solidify. 6) The casting is removed, processed, and polished.

Sand mold casting using wood patterns has been in existence for a long time, while the basic patents for FMC were granted in 1958 in the US, making it a new method of casting. In comparison with wood pattern-based sand mold casting, FMC is a process innovation that obviates the need to separate top and bottom, the removal of patterns, and cores (Kanno, 2004). Because FMC does not separate top and bottom, it does not have a burr at the joint in the final product. Because FMC does not require the removal of the pattern, there is no 
need for designs to consider the manner in which patterns are to be removed. Because there is no core, designing complex shapes is greatly simplified. Creating such complex shapes using wood pattern-based sand mold casting required highly developed skills; however, these are not necessary with FMC.

According to Ozerov, Shuliak, and Plotnikov (1971), the per capita productivity for simple casting by FMC improved approximately three times that for wood-pattern based sand mold casting. The cost to produce patterns equivalent to 22-ton castings was approximately $\$ 17,000$ using wood pattern, while only $\$ 1,700$ using foam polystyrene patterns. In one casting shop for an automobile factory, the implementation of FMC resulted in a $30 \%$ reduction in pattern-related labor and a $25 \%$ reduction in model-related labor.

On the other hand, FMC does have its problems. Wood patterns in sand mold casting can be used almost permanently once created, and this is important for mass production. In FMC, however, melted metal is poured directly onto the pattern, making the pattern usable only once. This is not a problem for prototypes and single casting, but leads to issues with uniformity and cost in mass production. In addition, the surface of the mold is adversely affected by gasses released when the foam polystyrene is utilized by the melted metal. This is a major problem with melted metal permeating into the mold in different ways compared with traditional methods, and causing more scrap. Although FMC is in principle superior, scrap leads to excessive costs.

As a result, many companies showed an interest in FMC, but did not find it marketable, and thus their interest waned. However, Kimura Chuzosho Co., Ltd is one company that has used FMC and been successful in replacing wood pattern-based sand mold casting in the marketplace.

The casting of machine tools often involves mass production, and the production volume share of Kimura Chuzosho in that market was 
$10 \%$ in 2000 , exceeding $20 \%$ in $2005 .{ }^{5}$ Despite conventional wisdom proclaiming that FMC is difficult to use, excluding large-scale casting, Kimura has expanded their market share in that area. Their success can be attributed to two points: their accumulation of innovations and the use of IT. We describe both of these below.

\section{Kimura's Development of FMC}

Kimura Chuzosho specializes in casting. Since its establishment in 1927, the company has produced castings for pumps and diesel engines using wood pattern-based sand mold casting. The year 1966 was a time of change for the company. In 1965, Yuka Badische Limited became a licensee of the FMC process in Japan, and began sub-licensing FMC to domestic casting companies. At its height, it had reproduction agreements with approximately 120 companies with Kimura Chuzosho becoming one of them in July 1966.

During that time, motorization led to increased demand for large-scale single casting for automobile press molds. These molds differ in shape and complexity by model, and frequent automobile model changes require short delivery times. These requirements make FMC a very useful method. When FMC was first introduced in Japan, however, its future turned unclear. The process required different know-how than sand mold casting with wood patterns, leading to repeated failures in companies that used FMC to make prototypes. Most of such companies gave up on the idea of using FMC. After acquiring a license to use FMC, Kimura Chuzosho similarly attempted production using that method. First, it could

5 Casting industry market share data reported herein is based on production volumes in Japan. The production volume of the overall market was obtained from METI's Yearbook of Machinery Statistics, and production volumes for Kimura Chuzosho was obtained from that company's internal documents. 
only find technical information limited to the ideas and principles behind FMC, and the company's efforts generated poor quality results with more scrap.

In response, Kimura Chuzosho accepted the challenge of practically applying FMC. Using an immature technology such as FMC was a huge gamble; however, once Kimura made the decision to do so, it began in earnest by investing in FMC equipment, building factories, and creating a hardworking shop floor. ${ }^{6}$ Kimura's continual process innovation and equipment investment enabled them to develop competitive advantages, and became major factors in their success (Tomita \& Takamatsu, 2013).

FMC was not successful when used under the same conditions as sand mold casting with wood patterns. Optimal casting conditions, such as the temperature of the melted metal and materials, were determined by solidifying values for numerous variables, and subsequently using those values continually for a certain period. In 1970, the company began using a 5-ton low-frequency induction furnace that enabled them to operate at low volumes for consecutive days and to stabilize the casting temperature, both of which were difficult.

In addition, Kimura held meetings to discuss countermeasures for scrap on a daily basis. For some time, they did not know the reason for the scrap, but engineers and shop floor employees alike discussed the topic together, providing feedback used in refining the casting conditions, and gradually standardizing and improving quality and productivity. It took them two or three years to finally consider prospects for the technology (Kimura Chuzosho, 2007).

The casting industry during that time was split into two types: companies that created patterns and those that performed casting.

6 It has been noted that, as a backdrop to this work, company executives had a strong desire for growth and their decision making continually focused on markets and corporate fitness (Matsushima, 2009). 
FMC generated a great deal of scrap; however, subsequent production of molds required orders for more patterns because patterns ended up being utilized by melted metal. Nevertheless, outsourcing took time and money. This eventually led Kimura Chuzosho to establish FM Pattern Factory for creating patterns for the FMC process in 1967. Linking the pattern and casting processes led to cost reductions and faster lead times, which became strengths for Kimura (Fujiwara \& Tsumita, 2009).

In 1971, Kimura established a machining factory for casting inspections, installing material testing equipment for materials research to improve quality. This series of efforts led Kimura's production volume share in the press mold casting market rise from $12 \%$ in 1969 to $18 \%$ in 1973.

Kimura Chuzosho continued to improve and refine the FMC process, and by 1975 the company had raised their technological level such that they could explore the field of machine tools. They called their proprietary, practical technology "New FMC." Nevertheless, production volumes for machine tools constituted only a small share compared with the volumes for press molds in the company.

Kimura made a major decision to stop the use of wood pattern-based sand mold casting in 1976. Wood patterns were a means to strengthen ties with customers in the casting industry, and FMC patterns did not hold this benefit because the patterns ended up being utilized by melted metal. Thus, the decision to do away with wood pattern-based sand mold casting required tremendous courage (Kimura Chuzosho, 2007). ${ }^{7}$

Under these circumstances, Kimura Chuzosho decided to make a

7 Factors in removing the yoke of the existing value network and acquiring new customers were allocation of resources during a time of rapidly declining demand in the business, a technology-centric corporate mission, and open external relationships (Miyazaki, 2013). 
complete transition to FMC due to the following four aspects (Kimura Chuzosho, 2007): 1) Progress made in improving and refining FMC technology and the removal of most technical concerns; 2) the strong growth in the automobile mold business; 3) success in commercializing machine tool casting through new FMC research; and 4) the parallel use of both FMC and sand mold casting with wood patterns that had reached its limits in terms of efficiency. ${ }^{8}$

Kimura developed a system called "fixed pouring, fixed shake-out, and fixed molding system" in its new factory in 1981. It aimed to fix its locations for pouring melted metal, shake-out, and molding. This solution immensely contributed to Kimura's productivity.

In 1982, Kimura Chuzosho installed three-dimensional numerical control (NC) machines, which dramatically improved the accuracy of pattern creation. Until that time, patterns with three-dimensional surfaces such as press molded roofs and fenders were all handmade. This not only took time but also made it nearly impossible to generate smooth curves. Thus, the company could only supply castings with extra processing margins between 15 and $30 \mathrm{~mm}$. Kimura focused its efforts on automation using NC machines, working in partnership with a wood machining equipment manufacturer to develop a three-dimensional NC machine specifically for FMC. Kimura's production volume share of the press mold casting market rose to $29 \%$ by 1986 .

In 1988, Kimura established the extremely large Omaezaki factory for large-scale molds casting, such as integrated side panels for automobile bodies. Kimura's orders for these panels exploded as Japan entered the expansion phase of the bubble economy in the late 80 s.

Kimura developed a new slury of carbon for coatings in 2000 that

$8 \mathrm{FMC}$ is also viewed as a competency-destroying innovation against wood pattern-based sand mold casting as there is difficulty in the parallel use of both technologies (Tushman \& Anderson, 1986). 
facilitated cleaning of the mold surfaces to protect the sandy surface of the mold from the heat of the melted metal. This served the purpose of improving casted surfaces and preventing burning of the mold. In the case of FMC, the need for a slury of carbon for coatings to protect the mold surface from the cinders of the foam polystyrene was even greater than for wood-pattern based sand mold casting. A slury of carbon for coatings in FMC allows gas from foam polystyrene to escape, but does not allow the melted metal to escape. The company thus needed to meet these conflicting needs. Including test equipment, the company invested more than 200 million yen over three years in development, and succeeded in developing a slury of carbon for coatings that achieved the above goals.

Improving the slury of carbon for coatings revealed other issues, namely the poor release of gasses. The company conducted research into improving ventilation, sand blending methods, and melted metal pouring, making further refinements in casting technologies. Its development and refinement in these areas dramatically improved mold surface quality, greatly reduced manhours required for finishing, and improved finishing productivity to $150 \%$.

\section{Achieving Mass Production}

Computer aided design (CAD)/computer aided manufacturing (CAM) systems support design and manufacturing, and became popular in the manufacturing industry in the 1980s. In 1987, Kimura Chuzosho developed a CAD/CAM system that enabled the company to create CAM data from user-generated CAD data, and subsequently create patterns using NC machines and blocks of foam polystyrene. This enabled the company to begin mass production of patterns and to develop mass production for machine tool casting. Nevertheless, the yield at the time was only approximately $20 \%$. First, only approximately $30 \%$ of patterns were produced internally, and 
limits on computer processing power meant a great deal of manual work. This manual work required ten years of experience, and there was often a great disparity in the competence of workers. ${ }^{9}$

Kimura equipped itself with engineering workstations in 1995, and purchased the CAD/CAM package "CADCEUS" in 1996. However, calculations that today only take one minute at the time took two hours. Even so, the company invested excess capacity into the mass production of machine tools in an effort to expand production in 1995. Simultaneously, it established a new factory in Gunma to expand its pattern production capabilities.

Kimura's production volume share of the metal processing machinery casting market rose from $0.3 \%$ in 1987 to $4.0 \%$ in 1996 . Its share of the press mold casting market rose to 54\% by 1996 .

Soon, CAD began to be widely used among Kimura's customers, and the company began accepting CAD data from them. ${ }^{10}$ In doing so, Kimura headed even further in the direction of digital production of patterns. The company aimed for the full mechanization of pattern production in the Omaezaki Number 2 Factory in 1997, and at the time of plant startup it purchased four NC machines (bringing to a total of 19 in use through the Kimura Group), and also developed the "Pro/E" CAD/CAM software package.

In 1998, Kimura jointly developed automated CAM software with a third party software manufacturer, fully automating a process that until that time comprised manual design, calculation, and decision making by humans. In 1999, PC-based CAD/CAM software appeared in the market promising both high performance and low cost, and

9 IT is implemented because it was clear that it reduced cost and improved quality (Ichikohji, 2013). In the case of FMC, these benefits were unclear in the beginning.

10 The sharing of CAD data between corporations reduces the time it takes to solve problem, while also having the negative effect of increasing coordination between the same companies. It does not always result in a net benefit (Ku, 2004). 
Kimura replaced all of its workstations with PCs. The company implemented the "SolidWorks" CAD package across the board in 2000, and consolidated on "CADCEUS" for CAM in 2005.

Simultaneously, the company was moving forward with the development of NC-related equipment. In 1999, the company began using high-speed processing machinery designed for patterns, and developed a horizontal crimping machine in-house. In 2000, Kimura developed a vertical crimping machine with proprietary blades, an NC locate adsorption plate, and an indexing device with an NC attachment. In addition, the company developed an automated measurement device to measure machine tool castings in conjunction with an NC equipment manufacturer. This work in technology development led to dramatic improvements in the accuracy of patterns and the finished castings.

This series of efforts improved accuracy from $\pm 5 \mathrm{~mm}$ to $0-1.5 \mathrm{~mm}$, and CAD/CAM usage increased from 30\% in 1999 to $100 \%$ in 2002 . The company was successful in fully mechanizing the production of patterns via NC machining using three-dimensional (3D) solid CAD data. This mechanization enabled the company to withdraw from pattern creation that relies on individual skill. Furthermore, work that required 10 years of experience could now be performed by CAD operators with only one year of experience.

The dramatic rise in pattern-related productivity meant that the number of days to create patterns for press mold side panels was reduced from 20 days in 1996 to only seven days in 2012. Mechanizing pattern production allowed part-timers rather than skilled professionals to be responsible for the work, which helped reduce costs. Manufacturing lead times using sand mold casting with wood patterns required three months from design to actual casting, but Kimura was in the end able to reduce this lead time to approximately three weeks.

Even sand mold casting with wood patterns is now performed by 
using 3D CAD to design wood patterns and CAM software to produce them. However, 3D CAD/CAM has the benefit of enabling mass production with high pattern accuracy, and as the technology has also enabled mass production via FMC. The use of 3D CAD/CAM in the pattern process, as well as casting innovations, has improved quality and facilitated mass production. Kimura's production volume in the machine tool casting market rose to $23 \%$ in 2010 .

\section{Disruptive Innovation: A Case of Full Mold Casting}

Disruptive innovations may occur due to reduced product performance according to existing criteria, while they improve performance in other criteria, and end up as alternatives to existing products by improving performance according to existing criteria as well (Christensen, 1997).

In the large-scale casting market, the basic criterion of customers is mold surface quality. Without a certain level of quality, the casting cannot serve its purpose; however, achieving the requisite level of quality can cause cost issues. As opposed to wood pattern-based sand mold casting that achieve the sufficient mold surface quality, FMC suffered from poor quality. However, some customers welcomed shorter lead times despite lower quality because automobile mold companies could adjust surface quality of castings. FMC acquired customers who prioritized shorter lead times as their primary criteria, and thereafter FMC improved casting quality and productivity. This led to FMC's success in the automobile mold casting market. Furthermore, after success in the single machine tool casting market, which required higher mid-range casting surface quality, Kimura Chuzosho successfully began mass producing with shortened lead times and improved quality and accuracy for high-end, mass produced machine tool castings and the company won a higher market share. Thus, FMC is a disruptive innovation against wood 
pattern-based sand mold casting.

Did FMC allow for the acquisition of new, nonconsumer customers? Production for automobile mold casting and machine tool casting already occurred using wood-pattern based sand mold casting, and this production method had existing customers. Thus, FMC did not acquire nonconsumers. Were customers of automobile mold casting and machine tool casting, or customers for mass-produced castings for machine tools considered overshot customers? Developing low-end disruptive innovations is a low-cost business model (Christensen \& Raynor, 2003). As to automobile mold casting, automakers were fine with lower mold surface quality in return for shortened lead times, but customers did not approve lower quality in exchange for reduced cost. For machine tool castings, machine tool manufacturers do not adjust mold surface quality, and they demand high quality rather than shorter lead times. Moreover, mass production requires higher mold surface quality as well as replicable accuracy and production lead times, which are short enough to support mass production. In Japan's large-scale casting industry, FMC became a disruptive innovation that withdrew customers from wood-pattern based sand mold casting, and these customers had specific demands but were neither nonconsumers nor overshot customers.

The logic behind disruptive innovation is far simpler than the customer analyses provided by Christensen et al. (2004). Even if a company can acquire only a small portion of customers with particular, specific requirements using quality, cost, delivery (QCD)-related technologies, which are perhaps even toy-like in comparison with existing technologies, such company will have opportunities to improve overall QCD as its business continues. 


\section{References}

Christensen, C. M. (1997). The innovator's dilemma: When new technologies cause great firms to fail. Boston, MA: Harvard Business School Press.

Christensen, C. M., Anthony, S. D., \& Roth, E. A. (2004). Seeing what's next: Using the theories of innovation to predict industry change. Boston, MA: Harvard Business School Press.

Christensen, C. M., \& Raynor, M. E. (2003). The innovator's solution: Creating and sustaining successful growth. Boston, MA: Harvard Business School Press.

Christensen, C. M., \& Rosenbloom, R. S. (1995). Explaining the attacker's advantage: Technological paradigms, organizational dynamics, and the value network. Research Policy, 24(2), 233-257.

Danneels, E. (2004). Disruptive technology reconsidered: A critique and research agenda. Journal of Product Innovation Management, 21, 246-258.

Fujiwara, M., \& Tsumita, A. (2009). Kimura Chuzosho: IT wo kijiku to sita kakushinteki furumourudo chuzou sisutemu no kaihatsu [Kimura Chuzosho: The development of innovative full mold casting system based on IT]. IIR Case Study No. 09-03, Hitotsubashi University Institute of Innovation Research (in Japanese).

Ichikohji, T. (2013). The influence of introducing IT into production system: A case of Japanese animation (anime) industry. Annals of Business Administrative Science, 12, 181-197. doi: 10.7880/ abas. 12.181

Kanno, T. (2004). Furumourudo you mokei seisaku gijutsu no henka to seihin rei [The change of pattern making technology for full mold and examples of its product]. Chuzoukougaku, 76(8), 671-678 (in Japanese).

Kimura Chuzosho (2007). Kimura Chuzosho 80 nen no ayumi [History of the 80 years of Kimura Chuzosho]. Shizuoka, Japan: Kimura Chuzosho (in Japanese). 
$\mathrm{Ku}, \mathrm{S} .(2004)$. Exploring the causal model of 3D-CAD technology: Interfirm communication and product development performance in Japanese automobile parts industry. Annals of Business Administrative Science, 3, 1-14. doi: 10.7880/abas.3.1

Matsushima, S. (2009). Gijutsu sentaku koso kigyou seichou no kaname [The technology choice is the key of the firm's growth]. In H. Itami \& Tokyo Rika Daigaku MOT Kenkyukai (Eds.), Nihon no gijutsu keiei ni igi ari [Having an objection to Japanese technology management] (pp. 126-155). Tokyo, Japan: Nihon Keizai Shinbun Shuppan (in Japanese).

Miyazaki, M. (2013). Kigyou ga value network no kubiki kara nogareru toki [The time firms get out of the restraint of value network]. Akamon Management Review, 12(2), 131-168 (in Japanese).

Ozerov, V. A., Shuliak, V. S., \& Plotnikov, G. A. (1971). Saishin furumourudo hou no riron to jissai [The latest theory of full mold casting and the practical side]. Osaka, Japan: Shin Nihon Chutanzo Kyokai (in Japanese).

Sood, A., \& Tellis, G. J. (2005). Technological evolution and radical innovation? Journal of Marketing, 69(3), 152-168.

Takahashi, N., Shintaku, J., \& Ohkawa, H. (2013). Is technological trajectory disruptive? Annals of Business Administrative Science, 12, 1-12. doi: $10.7880 /$ abas. 12.1

Takamatsu, T., \& Tomita, J. (2014, August). Disruptive innovation: A case of full mold casting. Paper presented at ABAS Conference 2014 Summer, University of Tokyo, Japan.

Tellis, G. J. (2006). Disruptive technology or visionary leadership? Journal of Product Innovation Management, 23, 34-38.

Tomita, J., \& Takamatsu, T. (2013). Low-end disruptive innovation no mechanism: Kabusikigaisha Kimura Chuzosho no jirei wo chushin ni [The mechanism of low-end disruptive innovation: With a focus on Kimura Chuzosho Co., Ltd.]. Akamon Management Review, 12(2), 89-130 (in Japanese).

Tushman, M. L., \& Anderson, P. (1986). Technological discontinuities and 
organizational environments. Administrative Science Quarterly, 31, 439-465.

Utterback, J. M., \& Acee, H. J. (2005). Disruptive technologies: An expanded view. International Journal of Innovation Management, 9(1), $1-17$.

Received October 30, 2014; accepted January 16, 2015 